\title{
Potencial energético e alternativas para 0 aproveitamento do biogás e lodo de reatores UASB: estudo de caso Estação de tratamento de efluentes Laboreaux (Itabira)
}

\author{
Energy potential and alternative usages of biogas and sludge from UASB \\ reactors: case study of the Laboreaux wastewater treatment plant (Itabira)
}

André Pereira Rosa', Lívia Cristina da Silva Lobato², Jorge Martins Borges ${ }^{3}$, Gilberto Caldeira Bandeira de Melo ${ }^{4}$, Carlos Augusto de Lemos Chernicharo ${ }^{5}$

\begin{abstract}
口
\section{RESUMO}

Este trabalho estuda o potencial de aproveitamento energético dos subprodutos biogás e lodo gerados na estação de tratamento de efluentes (ETE) Laboreaux em Itabira (MG), composta de reatores UASB, filtros biológicos percoladores e unidade de desaguamento do lodo por filtro prensa. Os subprodutos biogás e lodo foram caracterizados em termos quantitativos (produção) e qualitativos (composição e poder calorífico) durante 12 meses de monitoramento. Foram estudados dois cenários de aproveitamento energético dos subprodutos: (i) uso prioritário do biogás para a secagem térmica do lodo e o excedente de biogás para geração de eletricidade em motor de combustão interna; e (ii) uso prioritário do biogás visando à geração de eletricidade e ao aproveitamento do calor dos gases de exaustão para a secagem térmica de lodo. Para a análise desses cenários, utilizou-se o software CHEMCAD $^{\circledR}$ a fim de determinar as condições de queima do biogás em câmara de combustão e em motor de combustão interna, assim como na determinação dos balanços de massa e energia. O estudo analisou o potencial de aproveitamento dos subprodutos do tratamento como fonte de energia renovável para uso na própria ETE e para fornecimento a terceiros. No cenário 1, a geração de eletricidade é menor (atendendo 22,2\% da demanda de energia da ETE), mas a secagem térmica possibilita maior redução no volume final de lodo a ser disposto ou a eliminação completa de disposição final se o lodo seco final (com 10\% de umidade) for utilizado como combustível por terceiros. No cenário 2, a geração de eletricidade é capaz de suprir 57,6\% da demanda de energia da ETE, todavia o calor contido nos gases de exaustão não é suficiente para a secagem de todo o lodo desaguado, configurando uma menor redução na quantidade de lodo a ser disposto (13,5 ou 24,9\% de redução em massa, conforme a alternativa de remoção de umidade selecionada).
\end{abstract}

Palavras-chave: biogás; recuperação de energia; lodo; tratamento de esgoto; reatores UASB.

\section{ABSTRACT}

This work assesses the potential of energy recovery of the byproducts biogas and sludge produced at the Laboreaux wastewater treatment plant (WWTP), in Itabira (MG), which is integrated by UASB reactors, trickling filters and sludge dehydration unit (filter press). The byproducts biogas and sludge were quantitatively (production) and qualitatively (composition and calorific value) characterized during a monitoring period of 12 months. Two scenarios for energy recovery from the byproducts were considered: (i) priority use of biogas for sludge thermal drying and the excess of biogas being used for power generation in an internal combustion engine (ICE); and (ii) primary use of biogas for power generation and the heat of the engine exhaustion gases being used for sludge thermal drying. Biogas burning conditions into a combustion chamber and in an internal combustion engine, as well as mass and energy balances for each scenario, were assessed with the CHEMCAD ${ }^{\circledR}$ software. The study analysed the potential use of the byproducts as sources of renewable energy for use in the WWTP itself and to be offered to third party. In scenario 1 , the electricity generation is lower (fulfilling $22.2 \%$ of the WWTP energy demand), but thermal drying allows greater reduction of sludge volume to be disposed of, or the entire elimination of final disposal if the dry sludge (with 10\% moisture content) is used as fuel by the third party. As for scenario 2, the electricity generation is sufficient to supply $57.6 \%$ of the WWTP energy demand, nevertheless the heat contained in exhausted gases is not enough to dry the whole dehydrated sludge, configuring a lower reduction of sludge amount to be disposed of (13.5 or 24.9\% of mass reduction, depending on the moisture reduction alternative chosen).

Keywords: biogas; energy recovery; sludge; wastewater treatment; UASB reactors.

\footnotetext{
'Doutor em Saneamento, Meio Ambiente e Recursos Hídricos pela Escola de Engenharia da Universidade Federal de Minas Gerais (UFMG) - Belo Horizonte (MG); Professor Adjunto do Departamento de Engenharia Agrícola da Universidade Federal de Viçosa (UFV) - Viçosa (MG), Brasil.

2Doutora pelo Programa de Pós-Graduação em Saneamento, Meio Ambiente e Recursos Hídricos da Escola de Engenharia da UFMG - Belo Horizonte (MG), Brasil. ${ }^{3}$ Especialista em Engenharia Sanitária e Ambiental pela UFMG - Belo Horizonte (MG); Diretor Técnico do Serviço Autônomo de Água e Esgoto de Itabira - Itabira (MG), Brasil. ${ }^{4}$ Doutor em Ciências de Engenharia, Karlsruher Institut für Technologie, KIT, Alemanha. Professor Associado do Departamento de Engenharia Sanitária e Ambiental da UFMG Belo Horizonte (MG), Brasil.

${ }^{5}$ Doutor em Environmental Engineering, Newcastle University, NCL, Inglaterra. Professor Titular do Departamento de Engenharia Sanitária e Ambiental da UFMG - Belo Horizonte (MG), Brasil.

Endereço para correspondência: André Pereira Rosa - Departamento de Engenharia Agrícola - Sala 303 - Universidade Federal de Viçosa - Campus Universitário - $36570-000$ Viçosa (MG), Brasil - E-mail: andrerosa@ufv.br

Recebido: 04/09/13 - Aceito: 17/08/15 - Reg. ABES: 123321
} 


\section{INTRODUÇÃO}

O aumento do número de estações de tratamento de esgoto doméstico (ETEs) por meio de reatores anaeróbios de fluxo ascendente e manta de lodo (reatores UASB) tem resultado no incremento da geração de biogás e lodo, subprodutos desse processo de tratamento.

Para o lodo, antes mesmo do estudo e da compatibilização de alternativas para o seu processamento e a sua destinação final, faz-se necessário analisar as características do esgoto a ser tratado, as tecnologias de tratamento do esgoto, a taxa de produção de lodos, a legislação ambiental e os tipos de solos e agricultura regional para, assim, se propor uma alternativa de disposição que atenda de forma conjunta aos critérios ambientais, técnicos e econômicos (FERNANDES et al., 2001).

Entretanto, em geral a escolha do destino final para o lodo leva em consideração apenas alternativas já localmente disponíveis nas unidades de tratamento. As principais formas de destino final de lodo, no ano de 2005, para os 27 países integrantes da União Europeia, foram o uso agrícola (41\%), a incineração (19\%), o aterro sanitário (17\%), a compostagem (12\%) e outras aplicações (12\% - UE, 2011). Esse cenário vem se modificando nos últimos anos, tendo sido estimado que o uso dos processos térmicos no gerenciamento do lodo de ETEs, com fins energéticos, irá duplicar até o ano 2020 nos 12 países membros mais antigos da União Europeia, passando a corresponder a uma participação de 37\% das formas de destino final (KELESSIDIS \& STASINAKIS, 2012). O lodo, muitas vezes caracterizado como um resíduo passível de aterramento, pode se tornar fonte de energia após o desaguamento, evidenciando a mudança do paradigma para o seu destino final (COURTAUD et al., 2010). Esse cenário aponta para a tendência de aproveitamento do lodo visando à produção de energia em benefício das ETEs, muito embora os estudos nessa área ainda não sejam bem difundidos (DE SENA et al., 2007).

De acordo com Stasta et al. (2006), o crescimento do tratamento térmico de lodo de ETE nos países europeus é evidente. Avalia-se que o estudo e a escolha de alternativas mais vantajosas do ponto de vista do gerenciamento de lodo podem garantir a autossuficiência energética de uma ETE, além da possibilidade de utilização do excesso de energia elétrica para ser introduzida na rede de distribuição, a depender de estudos sobre a qualidade da energia gerada (HOUDKOVÁ et al., 2008). Fonts et al. (2009) apontam que o poder calorífico inferior do lodo digerido anaerobiamente e seco, com umidade de 5,3\%, é igual a 7,7 MJ.kg-1.

Tendência semelhante ocorre com o gerenciamento de biogás gerado nas ETEs, no sentido de seu aproveitamento energético. $O$ biogás de reatores anaeróbios tratando esgoto doméstico apresenta concentrações de metano $\left(\mathrm{CH}_{4}\right)$ de 70 a $80 \%$, de nitrogênio $\left(\mathrm{N}_{2}\right)$ de 10 a $25 \%$ e de dióxido de carbono $\left(\mathrm{CO}_{2}\right)$ de 5 a 10\%, sendo que os elevados teores de nitrogênio devem-se a parcela de $\mathrm{N}_{2}$ dissolvida no esgoto doméstico afluente aos reatores (Noyola et al., 2006). O poder calorífico do

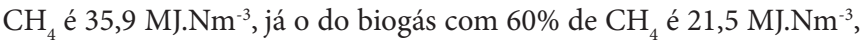

correspondendo a cerca de $70 \%$ do poder calorífico do gás natural. Na sua composição, o biogás pode conter ainda sulfeto de hidrogênio ( $\left.\mathrm{H}_{2} \mathrm{~S}\right)$ (1.000 a $2.000 \mathrm{ppm}$ ), que é corrosivo a materiais usados em equipamentos de aproveitamento térmico, como caldeiras, tubulações e motores. Segundo Holm-Nielsen et al. (2009), o conteúdo de $\mathrm{H}_{2} \mathrm{~S}$ no biogás, em níveis superiores a 300-500 ppm, pode causar danos às técnicas de conversão de energia.

O aproveitamento energético do biogás ainda é muito incipiente no Brasil, sendo que a grande maioria dos aterros sanitários e das estações de tratamento de esgoto doméstico e efluentes industriais apenas coleta e queima o biogás gerado, sem aproveitamento do seu potencial energético. Uma das principais vantagens da produção de energia em ETE relaciona-se ao fato de que toda a eletricidade gerada pode ser consumida no próprio local, sem a interferência de uma rede de distribuição (TSAGARAKIS, 2007). Adicionalmente, a digestão anaeróbia do lodo de esgoto doméstico pode, em muitos casos, produzir biogás suficiente para atender à demanda de energia necessária para a operação da planta (METCALF \& EDDY, 2003).

Para Salomon e Lora (2009), as principais vantagens da produção de energia elétrica pelo uso do biogás são:

1. geração descentralizada de energia, próximo da fonte consumidora;

2. possibilidade de lucro adicional devido à produção e à comercialização de energia, de acordo com as regras do sistema regulador do mercado de energia elétrica;

3. redução no consumo de eletricidade suprida externamente;

4. potencial de uso em processos para a cogeração de eletricidade e calor; e

5. redução das emissões de metano, que é um gás de efeito estufa.

Diante de uma situação de efetiva preocupação com a minimização do consumo de combustíveis fósseis e com o aumento dos custos e da demanda de energia para o tratamento de efluentes visando ao atendimento a padrões de qualidade do efluente final cada vez mais exigentes, destaca-se a importância da preocupação vigente com a concepção e operacionalidade, com o intuito de maximizar a eficiência energética e reduzir os gastos no tratamento (METCALF \& EDDY, 2003). Nesse contexto, este trabalho tem como objetivo contribuir com a avaliação do potencial energético do biogás e do lodo desaguado e com o estudo de alternativas de aproveitamento energético desses subprodutos em uma ETE.

\section{METODOLOGIA}

\section{Local de estudo}

O estudo foi desenvolvido na ETE Laboreaux, em Itabira (MG). A ETE foi projetada para atendimento de uma população de 123.000 habitantes 
(313 L.s s $^{-1}$ ), a ser atingida em 2029, com uma primeira etapa, atualmente em funcionamento, dimensionada para uma população de 70.000 habitantes $\left(170 \mathrm{~L} . \mathrm{s}^{-1}\right)$. Durante o período do estudo, a vazão média foi de aproximadamente de 80 L.s. ${ }^{-1}$.

A estação apresenta unidades de tratamento preliminar (gradeamento e desarenador) e de tratamento biológico anaeróbio e aeróbio em sequência (reator UASB, filtro biológico percolador - FBP - e decantador secundário). A Tabela 1 apresenta as principais características da ETE Laboreaux.

O biogás gerado nos reatores UASB é atualmente queimado em flare, sem aproveitamento energético. O lodo dos decantadores secundários é retornado aos reatores UASB, onde é adensado e estabilizado, seguindo, após o descarte, para a etapa de desaguamento, realizada por filtro prensa e, por fim, para o aterro sanitário da cidade de Itabira. Na unidade, existem ainda 4 leitos de secagem com área total de $600 \mathrm{~m}^{2}$, utilizados em caso de problemas operacionais do filtro prensa. A Figura 1 mostra uma vista geral das unidades da ETE Laboreaux. A Figura 2 apresenta um fluxograma das etapas relacionadas com o gerenciamento do lodo e do biogás na ETE.

\section{Caracterização do lodo}

O monitoramento da taxa de produção de lodo ocorreu no período de outubro de 2010 a outubro de 2011. O lodo foi quantificado pela pesagem do caminhão transportador após o carregamento de cada caçamba de estocagem do lodo desaguado antes do envio para o aterro sanitário da cidade de Itabira. O monitoramento para a caracterização do lodo foi realizada de abril de 2011 a junho de 2012 e a amostragem do lodo foi realizada quinzenalmente, consistindo da coleta de três pedaços de placas de lodo desidratado no filtro prensa, as quais eram maceradas e misturadas para a realização das análises de interesse: umidade, poder calorífico superior, composições elementar e imediata. Todas as análises foram realizadas em triplicata.

A determinação da umidade foi feita de acordo com os procedimentos estabelecidos nos Standard Methods (APHA/AWWA/WEF, 1998), a composição elementar (CHNO) foi determinada em Analisador CHNS modelo 2400, Série II, Perkin Elmer ${ }^{\circledR}$, e a composição imediata (sólidos fixos, voláteis e cinzas) de acordo com a Norma Brasileira (NBR) 8112 (ABNT, 2006). O poder calorífico superior real (PCS) do lodo, base seca (b.s), foi determinado em laboratório com o uso de uma bomba calorimétrica adiabática (tipo PARR 2081). Os poderes caloríficos superior $\left(\mathrm{PCS}_{\mathrm{s}}\right)$ e inferior $\left(\mathrm{PCI}_{\mathrm{t}}\right)$ teóricos foram determinados de acordo com as equações propostas pela fórmula de Dulong e por Cortez et al. (2008), respectivamente, como apresentado na Tabela 2.

\section{Caracterização do biogás}

A produção volumétrica de biogás foi realizada diariamente, também no período de outubro de 2010 a outubro de 2011. A medição foi feita por meio de um medidor mássico de vazão (modelo 640SFRQ-2734 ${ }^{\circledR}$ ) posicionado na linha de gás em um ponto anterior ao queimador (flare). A vazão medida de biogás foi considerada à pressão atmosférica padrão ( 1 bar) e à temperatura ambiente média $\left(25^{\circ} \mathrm{C}\right)$.

Nesse mesmo período, amostras de biogás foram coletadas em duplicata por meio de seringas plásticas equipadas com válvulas de três vias, em um ponto anterior ao queimador de gases. A caracterização do biogás com vistas à verificação do seu potencial energético foi realizada por cromatografia (cromatógrafo Perkin Elmer ${ }^{\circledast}$, detector TCD, fluxo de $17 \mathrm{~mL} . \mathrm{min}^{-1}$ com gás de arraste: hélio, coluna empacotada CARBOWAX ${ }^{\circledR}$,

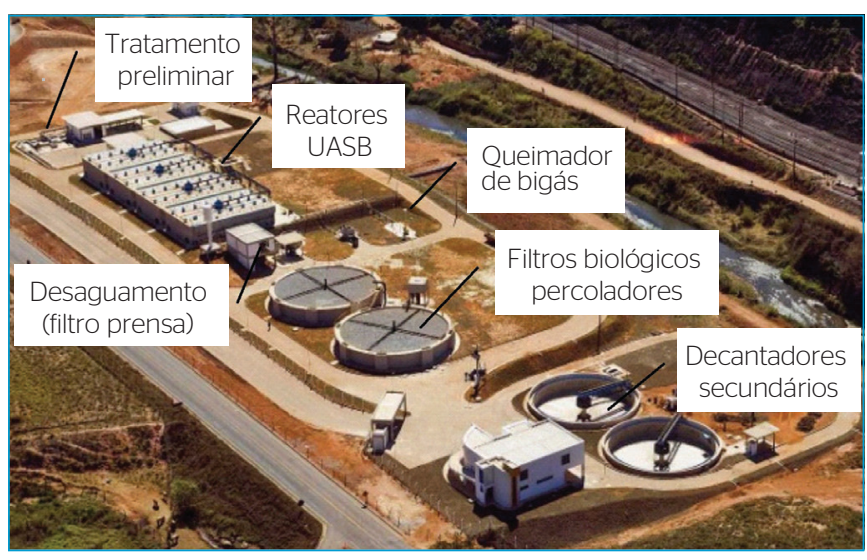

Figura 1 - Vista geral das unidades da estação de tratamento de esgoto Laboreaux.

Tabela 1 - Principais características da estação de tratamento de esgoto Laboreaux.

\begin{tabular}{|c|c|c|c|}
\hline Características & Reatores UASB & Filtros biológicos percoladores & Decantadores secundários \\
\hline População (hab.)* & \multicolumn{3}{|c|}{$70.000(123.000)$} \\
\hline Vazão $\left(m^{3} \cdot s^{-1}\right)^{\star}$ & \multicolumn{3}{|c|}{$0,170(0,313)$} \\
\hline Número de unidades* & $8(16)$ & $2(4)$ & $2(4)$ \\
\hline Tipo & Retangular & Circular & Circular \\
\hline Dimensões (m) & $21,7 \times 6,2$ & $D=22,5$ & $\mathrm{D}=20,0$ \\
\hline Área $\left(m^{2}\right)$ & 134,5 & 397,6 & 314,0 \\
\hline Profundidade útil (m) & 4,5 & 2,5 & 3,0 \\
\hline Volume útil $\left(m^{3}\right)$ & 605,4 & 994,0 & 942,0 \\
\hline Desaguamento do lodo & \multicolumn{3}{|c|}{ Filtro prensa* } \\
\hline
\end{tabular}

*Valores indicados entre parênteses referem-se ao fim de plano. 
sendo determinados os percentuais de $\mathrm{CH}_{4}, \mathrm{CO}_{2}$ e gases de mistura. A composição do biogás foi analisada, em média, duas vezes ao mês.

\section{Cálculo do balanço energético da Estação de tratamento de efluentes Laboreaux}

A partir dos dados operacionais da ETE e da caracterização do biogás e do lodo, foram determinadas as relações unitárias da produção de metano, de biogás e de energia nos reatores UASB. O cálculo do balanço energético corresponde à diferença entre a demanda energética na estação e o potencial energético dos subprodutos biogás e lodo. A demanda energética relaciona-se ao consumo de eletricidade na estação para a manutenção das atividades de operação do sistema de tratamento, essencialmente estações elevatórias de esgoto (EEE), operação do filtro prensa, fornecimento de eletricidade aos equipamentos de laboratório e iluminação. O potencial energético associa-se à energia máxima que poderia ser gerada com o aproveitamento energético do biogás. O lodo desidratado em filtro prensa foi considerado inadequado para fins energéticos (pelo excessivo conteúdo de umidade); a fim de viabilizar o seu potencial combustível, propõe-se sua secagem até a umidade de $10 \%$.

\section{Demanda energética da Estação de tratamento de efluentes Laboreaux}

A quase totalidade de demanda de energia na ETE Laboreaux está relacionada à operação de duas estações elevatórias de esgoto (EEE-1 e EEE-2) existentes na entrada da estação de tratamento. A primeira EEE bombeia o esgoto bruto, proveniente do emissário de chegada, após passar por uma unidade de gradeamento médio, alimentando os desarenadores da estação. A segunda EEE possibilita o encaminhamento do esgoto tratado em nível preliminar para a caixa distribuidora de vazão (CDV-1), que alimenta os oito reatores UASB da estação. As duas estações elevatórias são constituídas por poço de sucção,

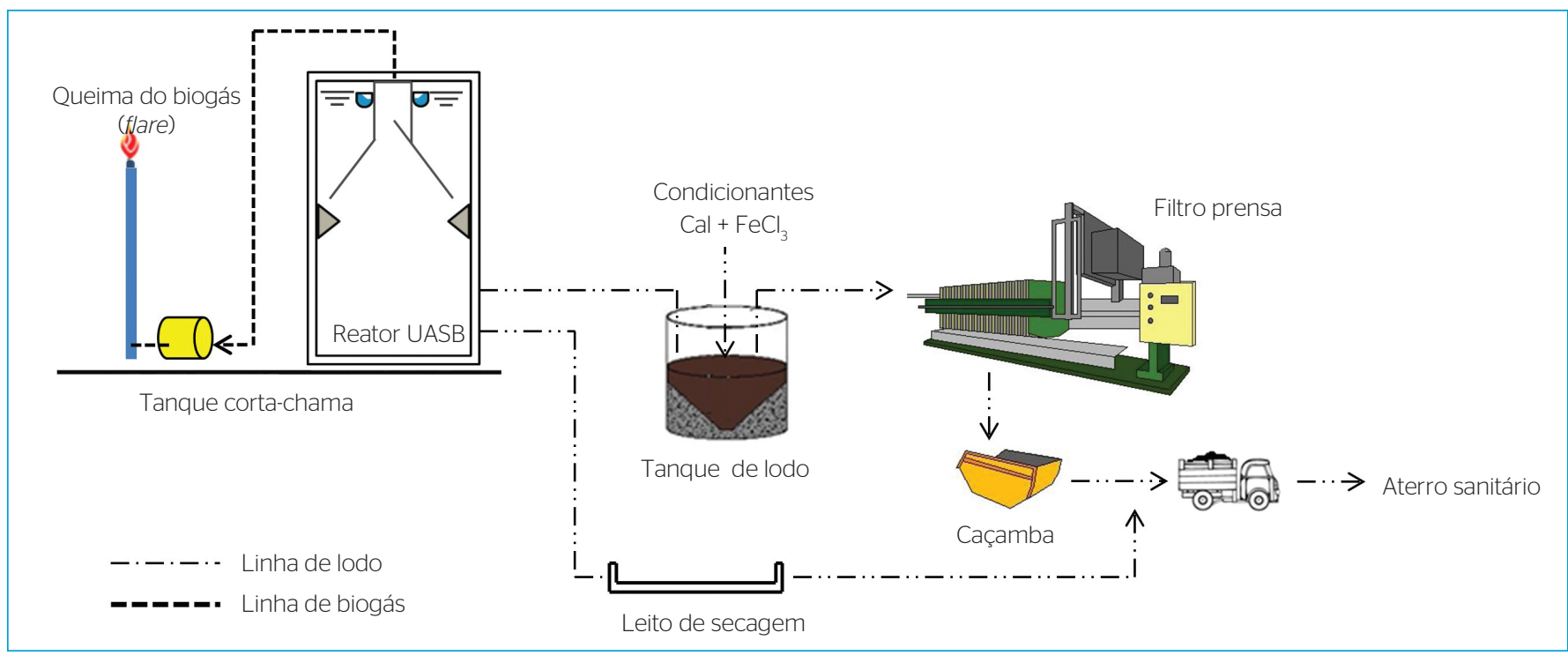

Figura 2 - Fluxograma esquemático das etapas relacionadas com o sistema de gerenciamento do lodo e do biogás na estação de tratamento de esgoto Laboreaux.

Tabela 2 - Procedimento de cálculo para a determinação dos poderes caloríficos superior e inferior teóricos para o lodo da estação de tratamento de esgoto Laboreaux.

\begin{tabular}{|c|c|c|}
\hline Parcelas & Equações & Observações \\
\hline \multirow{5}{*}{ Poder calorífico superior (PCS) teórico } & \multirow{5}{*}{$P C S_{s}=[337,3 \times C+1.418,9 \times(H-O 8)+93,1 \times S+23,3 \times N] 1.000$} & $\mathrm{PCS}_{\mathrm{S}}=$ poder calorífico superior, $\left(\mathrm{MJ} . \mathrm{kg}^{-1}\right)$, b.S. \\
\hline & & $\mathrm{C}=\%$ de carbono no material, b.s. \\
\hline & & O = \% de oxigênio no material, b.s. \\
\hline & & $\mathrm{S}=\%$ de enxofre no material, b.s. \\
\hline & & $\mathrm{N}=\%$ de nitrogênio no material, b.s. \\
\hline \multirow{4}{*}{ Poder calorífico inferior (PCI) teórico } & \multirow[t]{4}{*}{$P C I_{t}=\left[\left(P C S_{s}-\lambda \times\left(r+0,09 \times H_{s}\right)\right) \times\left(100-W_{t}\right) / 100\right]$} & $\mathrm{PCS}_{\mathrm{s}}=$ poder calorífico superior $\left(\mathrm{MJ} . \mathrm{kg}^{-1}\right)$, b.S. \\
\hline & & $\begin{array}{c}r=\text { razão entre teor de sólidos e teor de } \\
\text { umidade no lodo desidratado }\end{array}$ \\
\hline & & $\mathrm{H}=$ teor de hidrogênio (\%), b.s. \\
\hline & & $W_{t}=$ teor de sólidos no lodo desidratado (\%), b.t. \\
\hline
\end{tabular}

b. b.s.: base seca, b.t.: base de trabalho (umidade real da amostra após a coleta). Os dados da composição elementar são apresentados em de \% de massa. 
conjuntos motobombas e linha de recalque, representando os equipamentos de maior consumo energético na ETE. A Tabela 3 apresenta o resumo das principais características de projeto das EEE-1 e EEE2.

A demanda energética da ETE Laboreaux foi calculada a partir de dados de consumo ativo de energia fornecidos pelo SAAE de Itabira para os meses de outubro de 2010 a outubro de 2011 e consideram todos os gastos energéticos na estação (iluminação, consumo administrativo e laboratorial, operação do filtro prensa, bombas e demais equipamentos), conforme mostrado na Figura 3. A média de consumo de energia elétrica na ETE nesse período foi de 1.586 kWh.d ${ }^{-1}\left(5.709\right.$ MJ.d $\left.{ }^{-1}\right)$.

Tabela 3 - Principais características das elevatórias (EEE-1 e EEE-2) da estação de tratamento de esgoto Laboreaux

\begin{tabular}{l|c|c}
\hline Características & EEE-1 & EEE-2 \\
\hline$N^{\circ}$ de bombas & O4 & O4 \\
\hline Tipo & Reautoescorvante & Reautoescorvante \\
\hline Modelo & Gresco X-T 10 & Gresco X-T 10 \\
\hline Rotação de trabalho (rpm) & $950-1.000$ & $1.075-1.130$ \\
\hline Altura manométrica (mca) & 9,8 & 15,4 \\
\hline Potência instalada (kW) & 89,5 & 111,8 \\
\hline
\end{tabular}

EEE: estação elevatória de esgoto.

\section{Potencial energético dos subprodutos da Estação de tratamento de efluentes Laboreaux}

O potencial energético na ETE Laboreaux corresponde à somatória dos potenciais energéticos dos subprodutos do tratamento do esgoto: lodo e biogás. Na Tabela 4 são apresentadas as parcelas e as respectivas equações de cálculo do potencial energético da ETE.

\section{Proposta integrada de aproveitamento energético de lodo e biogás}

Dois cenários de aproveitamento energético dos subprodutos foram considerados no presente estudo, conforme detalhamento abaixo e ilustração na Figura 4. A Tabela 5 apresenta os dados de entrada utilizados em ambos os cenários, a fim de se determinar os balanços de massa e energia.

- Cenário 1: uso prioritário do biogás em câmara de combustão visando à geração de calor para a secagem térmica do lodo desidratado e ao excedente de biogás para geração de eletricidade em motor de combustão interna (MCI).

- Cenário 2: uso prioritário do biogás em MCI visando à geração de eletricidade e ao aproveitamento do calor dos gases de exaustão do motor para a secagem térmica de lodo.

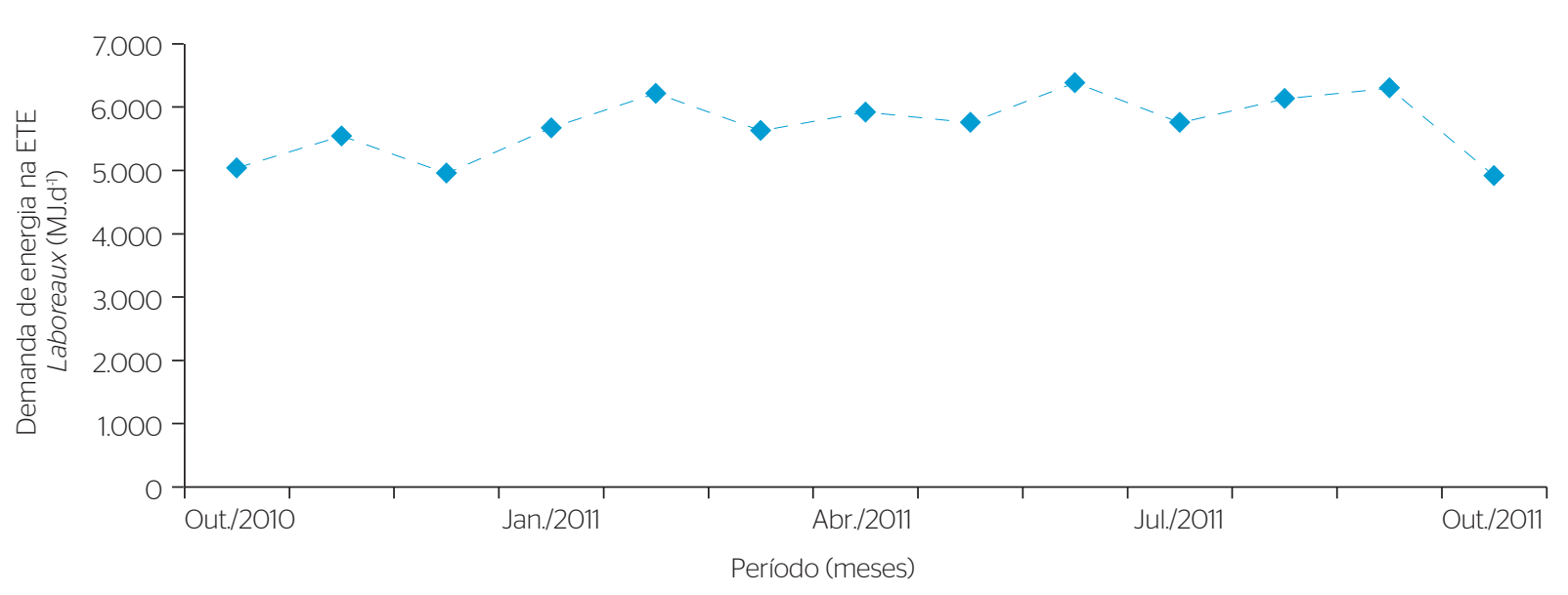

ETE: Estação de tratamento de efluentes

Figura 3 - Demanda de energia da estação de tratamento de esgoto Laboreaux para o período de outubro de 2010 a outubro de 2011.

Tabela 4 - Procedimento para o cálculo do potencial energético total da estação de tratamento de esgoto Laboreaux.

\begin{tabular}{|c|c|c|}
\hline Parcelas & Equações & Observações \\
\hline \multirow{3}{*}{$\begin{array}{l}\text { Potencial energético dos } \\
\text { subprodutos da ETE }\end{array}$} & \multirow{3}{*}{$P E_{\text {Total }}=P E_{\text {Biogás }}+P E_{\text {Lodo }}$} & $P E_{\text {Total }}=$ potencial energético total $\left({\left.\mathrm{MJ} . \mathrm{d}^{-1}\right)}\right)$ \\
\hline & & $P E_{\text {Biogás }}=$ potencial energético do biogás $\left(M J . d^{-1}\right)$ \\
\hline & & $P E_{L_{\text {odo }}}=$ potencial energético do lodo $\left(\mathrm{MJ} . \mathrm{d}^{-1}\right)$ \\
\hline \multirow{3}{*}{ Potencial energético do biogás } & \multirow{3}{*}{$P E_{\text {Biogás }}=Q_{\text {Biogás }} \times C_{\mathrm{CH} 4} \times E_{\mathrm{CH} 4}$} & $\mathrm{Q}_{\text {Biogás }}=$ produção medida de biogás $\left(\mathrm{Nm}^{3} \cdot \mathrm{d}^{-1}\right)$ \\
\hline & & $\mathrm{C}_{\mathrm{CH} 4}=$ concentração de metano no biogás (\%) \\
\hline & & $\mathrm{E}_{\mathrm{CH} 4}=$ poder calorífico inferior da combustão do metano $\left(35,9 \mathrm{MJ.Nm}^{3}\right)$ \\
\hline \multirow{2}{*}{ Potencial energético do lodo } & \multirow{2}{*}{$P E_{\text {Lodo }}=P_{\text {Lodo }} \times P C I_{t}$} & $\mathrm{P}_{\text {Lodo }}=$ produção de lodo desidratado $\left(\mathrm{kg} \cdot \mathrm{d}^{-1}\right)$ \\
\hline & & $\mathrm{PCl}_{\mathrm{t}}=$ poder calorífico inferior do lodo (MJ.kg'), b.t. \\
\hline
\end{tabular}

b.t: base de trabalho; ETE: Estação de tratamento de efluentes 
O software $\mathrm{CHEMCAD}^{\circledR}$ foi utilizado como ferramenta para a simulação dos processos de combustão (queima direta do biogás na câmara de combustão e no MCI). Para ambos os cenários, a combustão do biogás foi considerada adiabática com total oxidação do metano e excesso de oxigênio de $5 \%(\lambda=1,05)$. Outros dados considerados nas simulações são apresentados na Tabela 6.

\section{RESULTADOS E DISCUSSÃO}

\section{Potencial energético do biogás}

Algumas estatísticas descritivas referentes aos dados de vazão e à demanda química de oxigênio (DQO) do esgoto bruto afluente à ETE, e de vazão e composição de biogás gerado nos reatores UASB, durante o período de monitoramento da estação (outubro 2010 a outubro 2011), são apresentadas na Tabela 7.

A

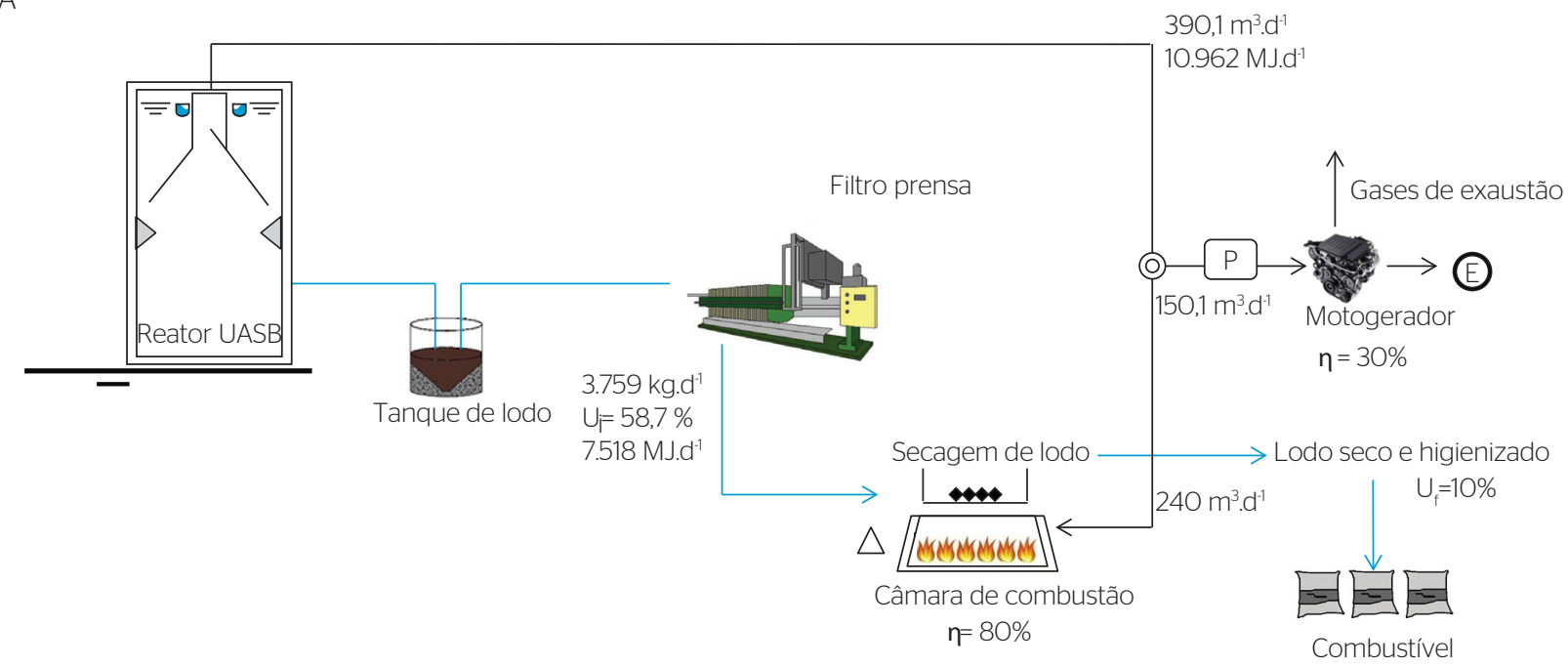

B

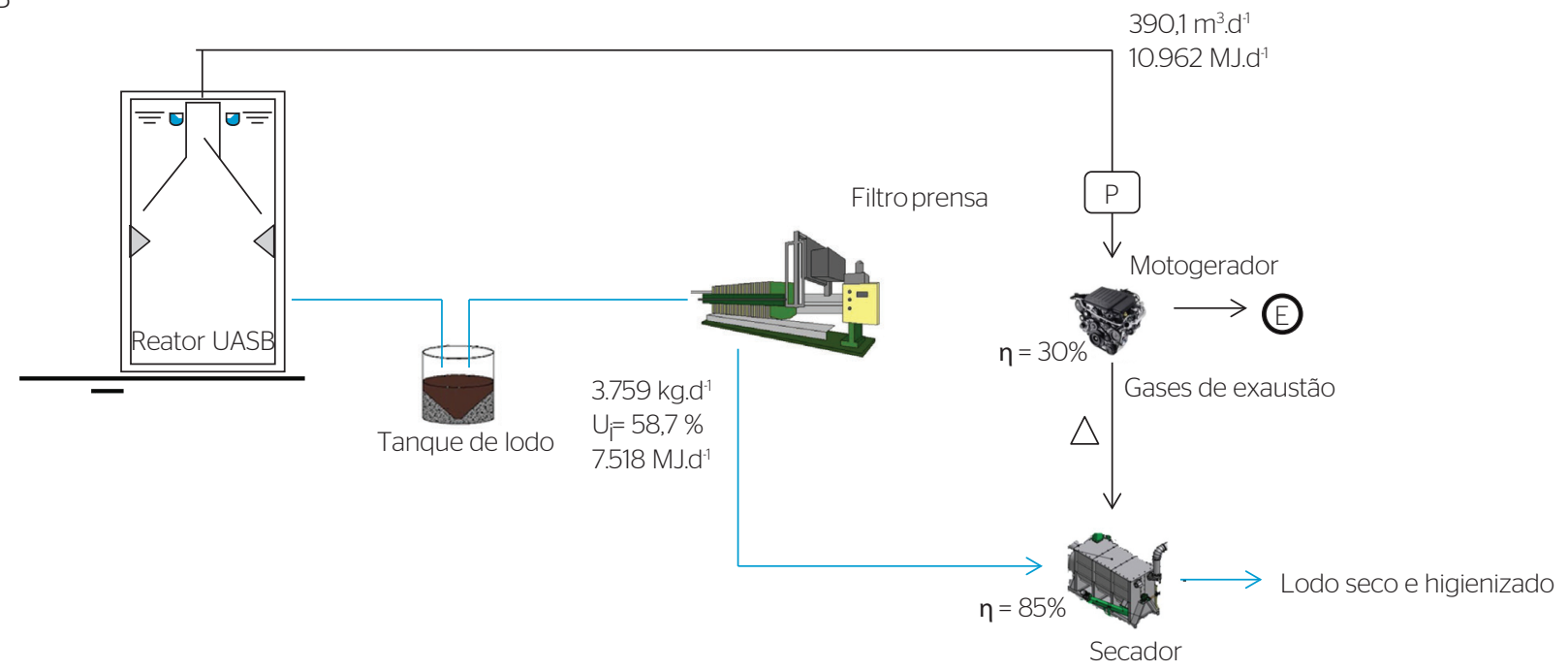

Figura 4 - Cenários para a recuperação energética dos subprodutos da estação de tratamento de esgoto Laboreaux: A cenário 1 - uso do biogás para a combustão e geração de calor para a secagem térmica do lodo, com o excesso do biogás utilizado para a geração de eletricidade; B cenário 2 geração de eletricidade, a partir de um motor de combustão interna utilizando biogás como combustível, com o aproveitamento do calor dos gases de exaustão do $\mathrm{MCl}$ para a secagem térmica de lodo desidratado. 
No período de monitoramento, a vazão de esgoto afluente à estação apresentou um valor médio de $6.751 \mathrm{~m}^{3} \cdot \mathrm{d}^{-1}\left(78 \mathrm{~L} \cdot \mathrm{s}^{-1}\right)$ e a produção volumétrica de biogás gerado nos reatores UASB, um valor médio de $390,1 \mathrm{Nm}^{3} \cdot \mathrm{d}^{-1}$. A composição média de biogás nesse mesmo período foi de 78,2\% de $\mathrm{CH}_{4}, 6,7 \%$ de $\mathrm{CO}_{2}$ e uma mistura de outros constituintes de $15,1 \%$. Observa-se uma contribuição de metano $(78,2 \%)$, dentro da faixa reportada por Noyola et al. (2006), de 70 a 80\%. A partir das características

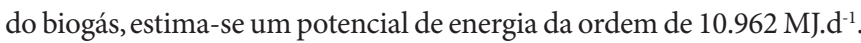

Tabela 5 - Dados de entrada para a avaliação dos cenários de recuperação energética dos subprodutos da estação de tratamento de esgoto Laboreaux.

\begin{tabular}{|c|c|c|c|}
\hline Item & Valor & Item & Valor \\
\hline \multicolumn{2}{|l|}{ Lodo desidratado (filtro prensa) } & \multicolumn{2}{|c|}{ Biogás (reator UASB) } \\
\hline Produção (kg.d-1) & 3.759 & Fluxo total $\left(m^{3} \cdot d^{-1}\right)$ & 390,1 \\
\hline Umidade (\%) & 58,7 & $\mathrm{CH}_{4}(\%)$ & 78,2 \\
\hline Poder calorífico superior (PCS ${ }_{\mathrm{s}}$, MJ.kg ${ }^{-1}$ & 8,7 & $\mathrm{CO}_{2}(\%)$ & 6,7 \\
\hline Poder calorífico inferior (PCl), $\mathrm{MJ}_{\mathrm{kg}}{ }^{-1}$ & 2,0 & Outros constituintes (\%) & 15,1 \\
\hline \multirow[t]{2}{*}{ Potencial energético (MJ.d-1) } & 7.518 & Potencial energético volumétrico $\left(\mathrm{MJ} \cdot \mathrm{m}^{-3}\right)^{2}$ & 28,1 \\
\hline & & Potencial energético $\left(\mathrm{MJ} . \mathrm{d}^{-1}\right)$ & 15.284 \\
\hline \multicolumn{2}{|l|}{ Características dos equipamentos ${ }^{1}$} & \multicolumn{2}{|c|}{ Características da ETE Laboreaux } \\
\hline Eficiência elétrica do $\mathrm{MCl}$ (\%) & 30 & Demanda de eletricidade $\left(\mathrm{MJ} . \mathrm{d}^{-1}\right)$ & 5.709 \\
\hline Eficiência do secador térmico a biogás (\%) ${ }^{3}$ & 80 & & \\
\hline Eficiência do secador a gás de escapamento $(\%)^{3}$ & 85 & & \\
\hline Calor nos gases de exaustão $(\%)^{4}$ & 25 & & \\
\hline Umidade do lodo após a secagem (\%) & 10,0 & & \\
\hline
\end{tabular}

'Valores considerados a partir de manuais técnicos de equipamentos. ${ }^{2}$ Calculado a partir de 35.9 MJ.Nm³ (Noyola et al., 2006) e da composição de metano. ${ }^{3}$ Eficiência global do equipamento para realizar a evaporação da áqua, considerando-se as perdas, como por radiação e convecção. ${ }^{4}$ Relação entre o calor contido nos gases de exaustão e a energia total do combustível (biogás) consumido pelo MCl, de acordo com Arteaga (2010). MCl: motor de combustão interna.

Tabela 6 - Características do processo de queima do biogás em secador (cenário 1) e em motores de combustão interna (nos cenários 1 e 2). No cenário 2, o secador irá aproveitar o calor residual dos gases de escapamento do motor de combustão interna.

\begin{tabular}{|c|c|c|c|c|c|}
\hline \multirow{2}{*}{ Dados } & \multirow{2}{*}{ Unidade } & \multicolumn{4}{|c|}{ Valor } \\
\hline & & \multicolumn{2}{|c|}{ Cenário 1} & \multicolumn{2}{|c|}{ Cenário 2} \\
\hline \multicolumn{2}{|l|}{ Biogás } & Secador & $\mathrm{MCl} 1$ & Secador & $\mathrm{MCl} 2$ \\
\hline Vazão (para T=25ㅇ e P=1 bar) & $m^{3} \cdot d^{-1}$ & 240 & 150,1 & - & 390,1 \\
\hline Fração de $\mathrm{CH}_{4}$ & $\%$ & - & 78 & - & 78 \\
\hline \multicolumn{6}{|l|}{$\mathrm{Ar}$} \\
\hline Vazão (para $\lambda=1,05, T=25^{\circ} \mathrm{C}$ e $\mathrm{P}=1$ bar) & $m^{3} \cdot d^{-1}$ & 3,14 & 3,83 & - & 6,97 \\
\hline Fração de $\mathrm{O}_{2}$ & $\%$ & 21 & 21 & - & 21 \\
\hline Fração de $\mathrm{N}_{2}$ & $\%$ & 79 & 79 & - & 79 \\
\hline \multicolumn{6}{|l|}{ Condições de queima } \\
\hline Temperatura dos gases de combustão' & ${ }^{\circ} \mathrm{C}$ & 900 & - & - & - \\
\hline Temperatura dos gases de escapamento do $\mathrm{MCl}$ & ${ }^{\circ} \mathrm{C}$ & - & 500 & $500^{2}$ & 500 \\
\hline Temperatura após as trocas de calor em secador & ${ }^{\circ} \mathrm{C}$ & 105 & - & 105 & - \\
\hline Excesso de ar $(\lambda)$ & fração & 1,05 & 1,05 & - & 1,05 \\
\hline
\end{tabular}

Temperatura calculada a partir da combustão do biogás e geração de calor nos gases resultantes, usados para a secagem. ${ }^{2} \mathrm{No}$ cenário 2, os gases de escapamento do MCl $\left(500^{\circ} \mathrm{C}\right)$ irão alimentar o secador; $\mathrm{MCl}$ : motor de combustão interna.

Tabela 7 - Estatística descritiva dos dados de vazão afluente, demanda química de oxigênio do esgoto e de produção de biogás na estação de tratamento de esgoto Laboreaux no período de outubro de 2010 a outubro de 2011.

\begin{tabular}{|c|c|c|c|c|c|c|}
\hline Estatísticas & $\begin{array}{l}\text { Vazão de esgoto } \\
\qquad\left(\mathrm{m}^{3} \cdot \mathrm{d}^{-1}\right)\end{array}$ & $\mathrm{DQO}_{\text {afluente }}\left(\mathrm{mg} \cdot \mathrm{L}^{-1}\right)$ & $\begin{array}{l}\text { Vazão de biogás } \\
\left(\mathrm{m}^{3} \cdot \mathrm{d}^{-1}\right)\end{array}$ & $\mathrm{CH}_{4}(\%)^{1}$ & $\mathrm{CO}_{2}(\%)^{1}$ & Outros (\%) \\
\hline Média & $6.750,6$ & 537,7 & 390,1 & 78,2 & 6,7 & 15,1 \\
\hline $\mathrm{N}^{\circ}$ de dados & 396 & 110 & 396 & 22 & 22 & 22 \\
\hline Mediana & $6.526,6$ & 553,0 & 432,5 & 79,4 & 6,8 & 13,1 \\
\hline Mínimo & $4.438,8$ & 118,0 & 126,7 & 70,3 & 4,4 & 6,0 \\
\hline Máximo & $12.101,4$ & $1.341,0$ & 584,0 & 82,5 & 8,7 & 17,1 \\
\hline$\sigma$ & $1.195,7$ & 49,8 & 165,2 & 2,7 & 1,3 & 3,7 \\
\hline
\end{tabular}

๔: desvio padrão em relação ao valor médio. 'Porcentagem em volume; DQO: demanda química de oxigênio. 


\section{Relações unitárias e aderência dos dados reais aos dados teóricos}

A partir dos dados de monitoramento, foram calculadas as relações unitárias de produção de metano, de biogás e de energia para a ETE Laboreaux no período em questão (2010 e 2011), as quais podem fornecer subsídios quando da avaliação da alternativa mais viável para a conversão energética do biogás (Tabela 8). Para referência, são apresentadas também as faixas de relações unitárias previstas pelo modelo de Lobato et al. (2012).

Avalia-se que todas as relações unitárias calculadas para a ETE Laboreaux estão de acordo com as faixas estimadas por Lobato et al. (2012), que desenvolveram um modelo para a estimativa do balanço de massa da conversão da DQO e do potencial de recuperação de energia em reatores UASB tratando esgoto doméstico. Nesse modelo, foram consideradas todas as parcelas envolvidas na digestão anaeróbia, inclusive possíveis perdas, a saber:

1. parcela da DQO inicial que é convertida a metano presente no biogás;

2. parcela da DQO inicial convertida a metano que escapa dissolvido no efluente do reator anaeróbio e com o gás residual (perdas);

3. parcela da DQO devida à redução de sulfato;

4. parcela da DQO que é convertida em lodo; e

5. parcela da DQO que permanece no efluente final.

\section{Potencial energético do lodo}

Como já especificado anteriormente, o lodo gerado na ETE Laboreauxé desidratado em um filtro prensa e segue para aterro sanitário. Durante o período de monitoramento, o filtro prensa operou por 226 dias e produziu
$849,5 \mathrm{t}$ de lodo desidratado, destinadas ao aterro municipal. Para efeito de cálculo, a parcela de lodo desidratado no leito de secagem, diante de problemas operacionais do filtro prensa (março de 2011), não foi considerada.

A Tabela 9 apresenta a estatística descritiva para a caracterização do lodo gerado na unidade de desaguamento por filtro prensa na ETE Laboreaux. De forma complementar, os gráficos box plot (Figuras 5 e 6) apresentam a variabilidade dos resultados de composição de lodo prensado. Identifica-se um potencial energético do lodo da ordem de 7.518 MJ.d ${ }^{-1}$ a partir do material com umidade de 58,7\%.

Em comparação com outros tipos de lodo biológico, observa-se que os valores de carbono e nitrogênio se encontram abaixo dos valores de caracterização de lodo reportados por Groß et al. (2008) e Fonts

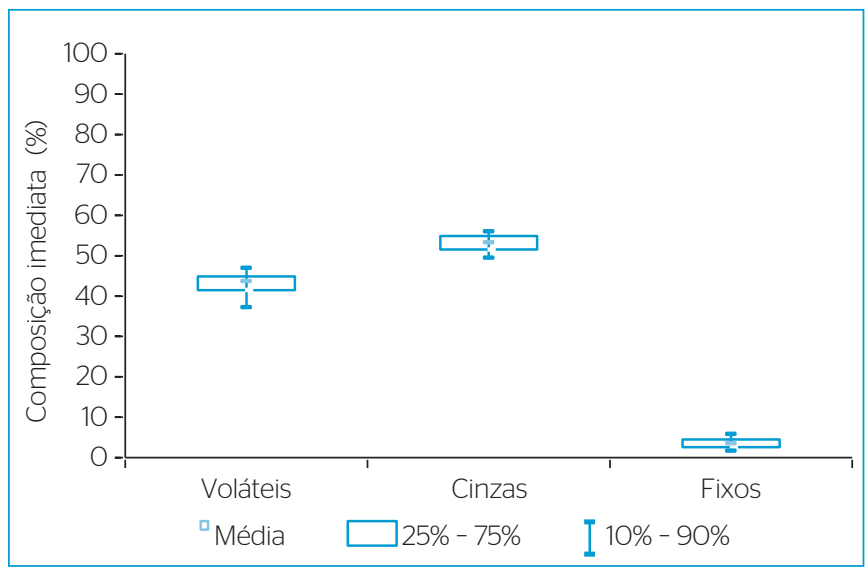

Figura 5 - Composição imediata do lodo desidratado por filtro prensa na estação de tratamento de esgoto Laboreaux, em base seca.

Tabela 8 - Relações unitárias de produção de metano, de biogás e de energia nos reatores UASB.

\begin{tabular}{|c|c|c|c|}
\hline \multirow{2}{*}{ Relações unitárias } & \multirow{2}{*}{ Unidades } & \multicolumn{2}{|c|}{ Valores } \\
\hline & & Medidos & Simulados' \\
\hline Volume de metano por volume de esgoto tratado & $\mathrm{m}^{3} \mathrm{CH}_{4} \mathrm{~m}^{3}$ esgoto tratado-1 & 0,06 & $0,07-0,14$ \\
\hline Volume de metano por DQO removida & $\mathrm{m}^{3} \mathrm{CH}_{4} \cdot \mathrm{kgDQO}_{\text {removida }}{ }^{-1}$ & 0,17 & $0,11-0,19$ \\
\hline Volume de biogás por volume de esgoto tratado & 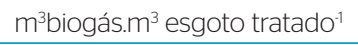 & 0,07 & $0,06-0,10$ \\
\hline Volume de biogás por DQO removida & $\mathrm{m}^{3}$ biogás.kgDQO ${ }_{\text {removida }}{ }^{-1}$ & 0,21 & $0,16-0,24$ \\
\hline Potencial de produção de energia por volume esgoto tratado & MJ.m³ esgoto tratado-1 & 2,0 & $1,5-2,9$ \\
\hline Potencial de produção de energia por DQO removida & MJ.kgDQO $_{\text {removida }}{ }^{-1}$ & 6,0 & $4,1-7,0$ \\
\hline Potencial de produção de energia por volume de biogás produzido & MJ.m³ biogás ${ }^{-1}$ & 28,1 & $25,1-28,7$ \\
\hline
\end{tabular}

'Faixa indicada por Lobato et al. (2012).

DQO: demanda química de oxigênio.

Tabela 9 - Estatística descritiva dos resultados de caracterização do lodo desidratado gerado na estação de tratamento de esgoto Laboreaux.

\begin{tabular}{|c|c|c|c|c|c|c|c|c|c|c|c|c|c|}
\hline \multirow{3}{*}{ Estatística } & \multirow{2}{*}{\multicolumn{3}{|c|}{$\begin{array}{l}\text { Composição imediata } \\
\text { (\% em massa - b.s.) }\end{array}$}} & \multirow{3}{*}{$\begin{array}{l}\text { Umidade } \\
(\%)\end{array}$} & \multicolumn{4}{|c|}{ Poder calorífico (MJ.kg $\left.{ }^{-1}\right)$} & \multirow{2}{*}{\multicolumn{5}{|c|}{ Composição elementar (\% em massa - b.s.) }} \\
\hline & & & & & \multicolumn{2}{|c|}{ Teórico } & \multicolumn{2}{|c|}{ Real } & & & & & \\
\hline & Voláteis & Cinzas & Fixos & & $\begin{array}{l}\text { PCS } \\
\text { (b.s.) }\end{array}$ & $\begin{array}{l}\mathrm{PCl} \\
\text { (b.t.) }\end{array}$ & $\begin{array}{l}\text { PCS } \\
\text { (b.s.) }\end{array}$ & PCI (b.t.) & C & $\mathrm{H}$ & $\mathrm{N}$ & $\mathbf{O}^{1}$ & Cinzas \\
\hline Média & 42,9 & 53,3 & 3,8 & 58,7 & 7,4 & 1,7 & 8,7 & 2,0 & 19,8 & 3,6 & 2,1 & 20,5 & 54,0 \\
\hline Número de dados & 31 & 31 & 31 & 29 & 27 & 27 & 26 & 24 & 19 & 19 & 19 & 19 & 19 \\
\hline Mediana & 43,7 & 53,3 & 3,6 & 58,2 & 7,4 & 1,5 & 8,6 & 1,9 & 19,6 & 3,5 & 2,0 & 20,0 & 53,9 \\
\hline$\sigma$ & 4,0 & 3,1 & 1,9 & 5,9 & 0,9 & 1,4 & 1,2 & 0,8 & 1,6 & 0,3 & 0,5 & 2,0 & 3,2 \\
\hline
\end{tabular}

b.s.: base seca; b.t.: base de trabalho; PCS: poder calorífico superior; PCl: poder calorífico inferior; $\sigma$ : desvio padrão em relação ao valor médio. 'Determinado por diferença. ${ }^{2}$ Considerados os dados medidos de cinzas para os dias em que houve caracterização de composição elementar. 
et al. (2009), entretanto o teor de hidrogênio é elevado quando comparado a Groß et al. (2008), Fonts et al. (2009), Courtaud et al. (2010) e Dogru et al. (2002).

Em comparação com outros tipos de biomassa, os valores de carbono $(\mathrm{C}=43,0 \%)$ e hidrogênio $(\mathrm{H}=7,8 \%)$ do lodo caracterizado neste estudo, em base combustível (desconsideradas as cinzas), apresentaram-se inferiores aos do eucalipto $(\mathrm{C}=49,3 \% ; \mathrm{H}=5,9 \%)$, casca de arroz $(\mathrm{C}=53,7 \% ; \mathrm{H}=5,8 \%)$ e bagaço de cana $(\mathrm{C}=49,3 \% ; \mathrm{H}=5,9 \%)$, conforme reportado por Jenkins (1990) apud Cortez et al. (2008).

O diagrama de van Krevelen, concebido para a análise do nível de carbonificação de diferentes tipos de combustível (VAN KREVELEN \& SCHUYER, 1957), avalia as propriedades energéticas dos combustíveis livres de água e cinzas. A Figura 7 evidencia que a relação H/C é compatível com a caracterização de lodo biológico desidratado em outras pesquisas, enquanto a razão O/C é significativamente maior. Uma possível explicação é o fato de que o reator UASB na ETE Laboreaux recebe o lodo secundário gerado a partir dos filtros biológicos percoladores (aeróbios).

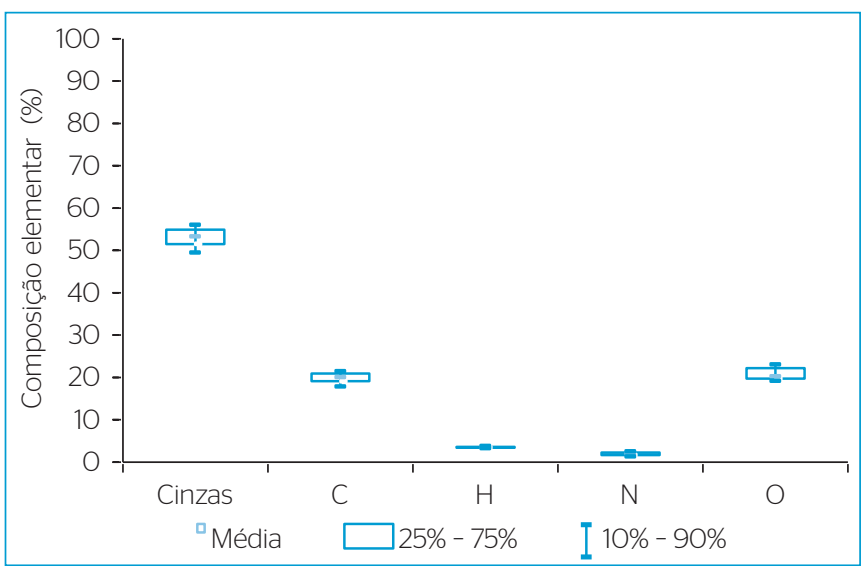

Figura 6 - Composição elementar do lodo desidratado por filtro prensa na estação de tratamento de esgoto Laboreaux, em base seca.

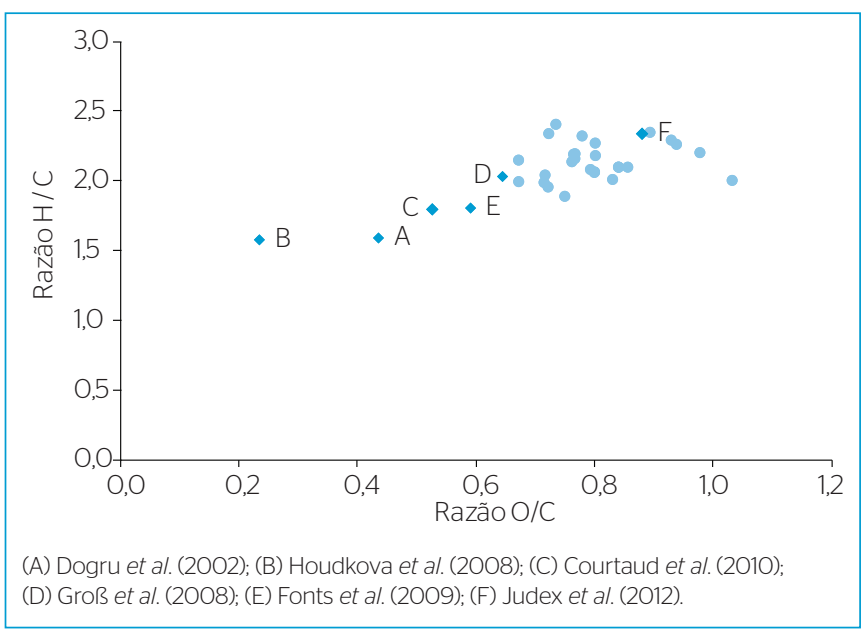

Figura 7 - Correlação das razões atômicas de H/C e O/C para o lodo de filtro prensa da estação de tratamento de esgoto Laboreaux e comparação com outros autores.
O lodo apresenta características similares às reportadas por Judex et al. (2012) para a ETE de Balingen (Alemanha), a qual possui recuperação energética dos subprodutos lodo e biogás, com a cogeração de energia em um motor de combustão interna (MCI), a partir da mistura do biogás da digestão anaeróbia e do syngas gerado na gaseificação do lodo.

No que se refere aos resultados de potencial energético do lodo, nota-se, em linhas gerais, que os valores medidos em laboratório são ligeiramente superiores aos estimados pela equação de Dulong

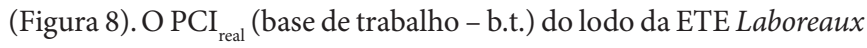
(2,0 MJ.kg-1 a uma umidade de 58,7\%) é inferior ao reportado por Fonts et al. (2009), igual a 7,7 MJ.kg-1 a uma umidade de 5,3\%, o que evidencia a influência da secagem sobre o poder calorífico.

Considerando a secagem do lodo para umidade final de $10 \%$ e teor de hidrogênio de 3,6\%, o PCI ${ }_{\text {real }}$ (b.t.) do lodo seco final corresponderia a 4,5 MJ.kg-1. Esse seria o valor energético do lodo para uso em geração térmica (caldeiras, aquecedores, etc.) ou em termelétricas. No caso de ETEs, a baixa demanda interna por energia térmica não justifica a queima do lodo para uso próprio, e a quantidade de lodo gerado não viabiliza a geração termelétrica. No entanto, o lodo seco poderá ser destinado a usuários comerciais ou industriais locais ou regionais, para substituir lenha ou carvão, e, nesse caso, mesmo que não haja retorno financeiro, a simples destinação energética do lodo representa uma economia, pois deixaria de ser transportado e disposto em aterro.

\section{Estudo de alternativas de aproveitamento energético do biogás e lodo}

\section{Cenário 1 - Uso prioritário do biogás para secagem térmica do lodo}

Nesta alternativa, o objetivo principal é promover a secagem térmica do lodo por meio do uso do biogás como fonte de calor e, de forma

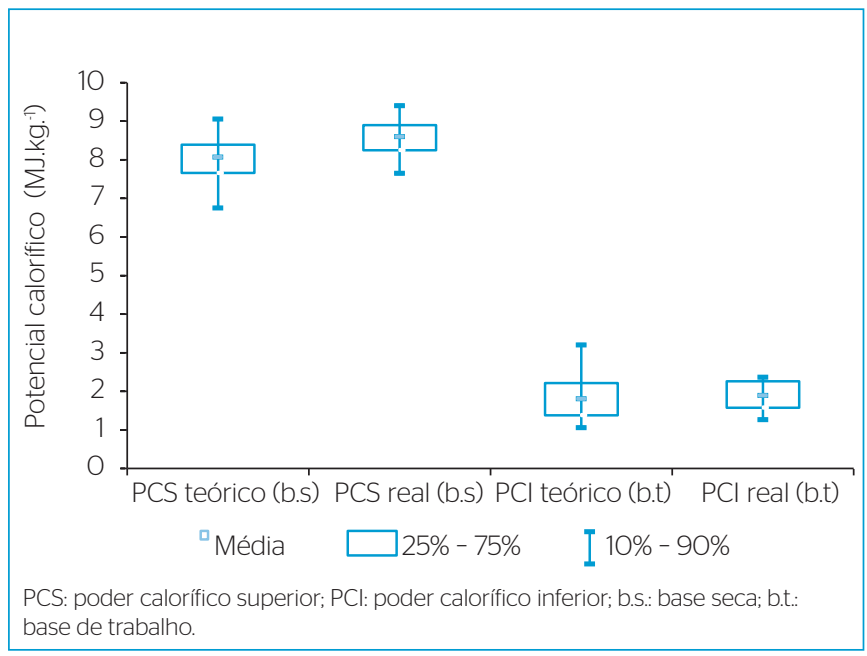

Figura 8 - Poder calorífico superior e inferior, teóricos e reais, para o lodo de filtro prensa da estação de tratamento de esgoto Laboreaux. 
secundária, a geração de eletricidade, com o excedente de energia não empregado na secagem para benefício da ETE.

A Figura 9 apresenta um balanço de massa e energia para o cenário 1. Pode-se observar que o processo de evaporação demanda $61,5 \%$ da vazão do biogás produzido na ETE, com o remanescente $(38,5 \%)$ empregado na geração de eletricidade. A Tabela 10 apresenta o balanço energético para o cenário avaliado, assim como os dados relevantes das condições de entrada e saída do processo.

A partir do potencial energético total do biogás $\left(4.218 \mathrm{MJ}^{\mathrm{d}} \mathrm{d}^{-1}\right) \mathrm{e}$ de um rendimento de conversão no conjunto motogerador de $30 \%$, a

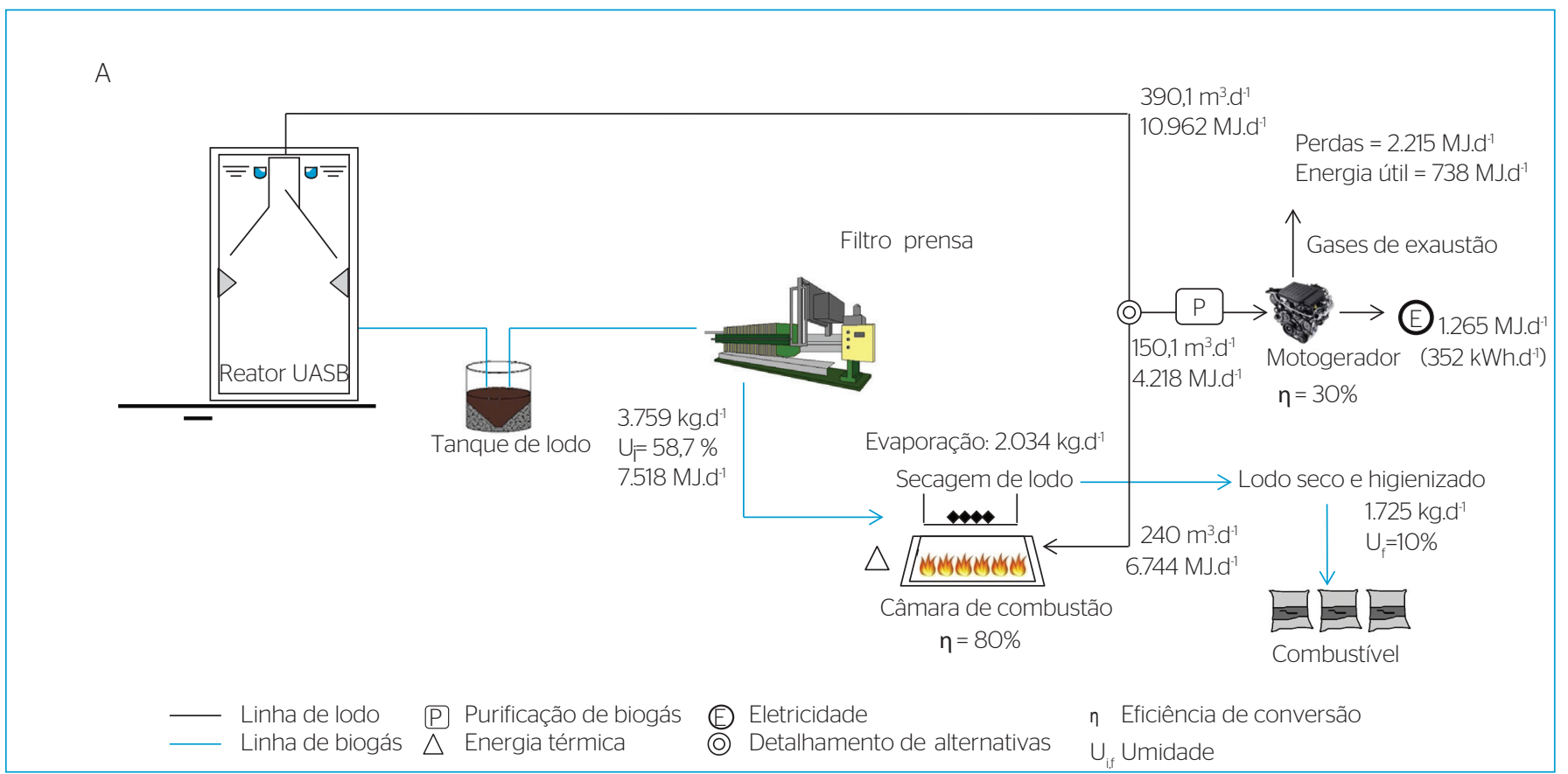

Figura 9 - Balanço de massa e energia para o aproveitamento energético do biogás para a secagem térmica do lodo desidratado na estação de tratamento de esgoto Laboreaux - cenário 1.

Tabela 10 - Balanço de massa e energia para o cenário 1.

\begin{tabular}{|c|c|c|c|c|c|c|c|}
\hline \multirow[b]{2}{*}{ Item } & \multicolumn{3}{|c|}{ Produtos iniciais } & \multirow{2}{*}{$\begin{array}{l}\text { Perdas } \\
\left(\mathrm{MJ}^{\left.-d^{-1}\right)}\right.\end{array}$} & \multicolumn{3}{|c|}{ Produtos finais } \\
\hline & Fluxo & $\begin{array}{c}\text { Poder } \\
\text { calorífico }\end{array}$ & $\begin{array}{c}\text { Potencial } \\
\text { energético }\left(M J . d^{-1}\right)\end{array}$ & & Fluxo & $\begin{array}{l}\text { Poder calo- } \\
\text { rífico }\end{array}$ & $\begin{array}{c}\text { Potencial } \\
\text { energético }\left({\left.\mathrm{MJ} . \mathrm{d}^{-1}\right)}^{-1}\right.\end{array}$ \\
\hline
\end{tabular}

Produtos recebidos da estação de tratamento de esgoto

\begin{tabular}{|c|c|c|c|c|c|c|c|}
\hline Lodo (58,7\% umidade) & $3.759 \mathrm{~kg} \cdot \mathrm{d}^{-1}$ & 2,0 MJ.kg-1 & 7.518 & - & - & - & - \\
\hline Biogás & $390,1 \mathrm{~m}^{3} \cdot \mathrm{d}^{-1}$ & $28,1 \mathrm{MJ} / \mathrm{m}^{-3}$ & 10.962 & - & - & - & - \\
\hline Subtotal & - & - & 18.480 & - & - & - & - \\
\hline \multicolumn{8}{|c|}{ Balanço no motor de combustão Interna } \\
\hline Biogás consumido & $150,1 \mathrm{~m}^{3} \cdot \mathrm{d}^{-1}$ & $28,1 \mathrm{MJ} \cdot \mathrm{m}^{-3}$ & 4.218 & - & - & - & \\
\hline Energia elétrica gerada $(\eta=30 \%)$ & - & - & - & - & - & - & $1.265^{*}$ \\
\hline Perdas no sistema ${ }^{a}$ & - & - & - & 2.952 & - & - & \\
\hline Subtotal & & & 4.218 & 2.952 & - & - & $1.265^{\star}$ \\
\hline \multicolumn{8}{|l|}{ Balanço no secador térmico de lodos } \\
\hline Biogás consumido & $240,0 \mathrm{~m}^{3} \cdot \mathrm{d}^{-1}$ & $28,1 \mathrm{MJ} \cdot \mathrm{m}^{-3}$ & 6.744 & - & - & - & - \\
\hline Lodo desidratado alimentado & $3.759 \mathrm{~kg} \cdot \mathrm{d}^{-1}$ & 2,0 MJ.kg ${ }^{-1}$ & 7.518 & - & - & - & - \\
\hline Lodo seco final (10\% umidade) & - & - & - & - & $1.725 \mathrm{~kg} \cdot \mathrm{d}^{-1}$ & 4,36 MJ.kg-1 $^{-1}$ & $7.519 * c$ \\
\hline Evaporação da água ( $\eta=80 \%)$ & - & - & - & $5.411^{\mathrm{d}}$ & - & - & - \\
\hline Perdas no sistemab & - & - & - & $1.074^{\mathrm{e}}$ & - & - & - \\
\hline Calor residual na secagem & - & - & - & $259^{c}$ & - & - & - \\
\hline Subtotal & - & - & 14.262 & 6.744 & - & - & $7.519^{* c}$ \\
\hline TOTAL & - & - & 18.480 & 9.696 & - & - & $8.784^{*}$ \\
\hline
\end{tabular}

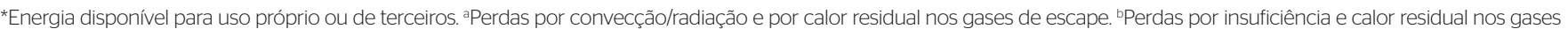

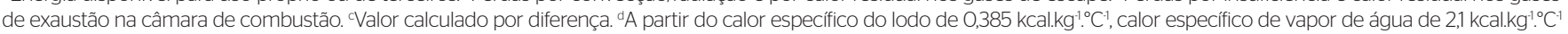
e calor de vaporização da áqua de 540 kcal.kg ${ }^{-1}$ para promover a secagem térmica do lodo de 57,8\% a 10\% de umidade. d+eValor calculado pelo aplicativo CHEMCAD ${ }^{\circledR}$. 
energia elétrica gerada (1.265 MJ.d $\left.{ }^{-1}\right)$ é suficiente para suprir $22,2 \%$ da demanda de eletricidade da estação $\left(5.709 \mathrm{MJ} \cdot \mathrm{d}^{-1}\right)$. O calor gerado no MCI pode eventualmente ser empregado para outros usos, mas esse aproveitamento não foi contemplado na concepção proposta.

O lodo a $10 \%$ de umidade pode ser considerado um potencial combustível, entretanto esse uso requer geralmente um processamento mecânico adicional (peletização e briquetagem). Como a demanda por energia térmica na ETE é pequena e a geração termelétrica com o emprego do lodo seco não é economicamente atrativa, considera-se que o melhor uso energético do lodo seco seria o seu fornecimento a potenciais usuários consumidores desse combustível. Mesmo gerando pouca ou nenhuma receita (caso venha a ser doado), a simples entrega do resíduo como subproduto já representa um barateamento na operação da ETE pela economia nos custos de transporte e disposição final do lodo em aterro sanitário.

Considerando o lodo seco ( $10 \%$ de umidade), a massa de material produzido no secador seria de $1.725 \mathrm{~kg} \cdot \mathrm{d}^{-1}$, com um poder calorífico inferior equivalente (b.t.) de 4,36 MJ.kg-1 . Esse lodo poderia fornecer 7.519 MJ.d $\mathrm{d}^{-1}$ caso utilizado como combustível por terceiros, eliminando totalmente a produção de rejeito final a ser destinado a aterro sanitário. A Tabela 11 apresenta o detalhamento do balanço de massa na secagem térmica do lodo a partir da queima de $240 \mathrm{~m}^{3} \cdot \mathrm{d}^{-1}$ de biogás na câmara de combustão.

\section{Cenário 2 - Uso prioritário}

\section{do biogás para a geração de eletricidade}

O cenário 2, ilustrado na Figura 10, tem como objetivo principal a produção de eletricidade para a ETE a partir do uso de todo o biogás produzido nos reatores UASB, seguido da secagem do lodo desidratado pelo calor contido nos gases de exaustão do MCI. A Tabela 12 apresenta o balanço de massa e energia detalhados. Neste cenário, seria possível a geração de $3.289 \mathrm{MJ} . \mathrm{d}^{-1}$ de eletricidade, o que corresponde a um suprimento de $57,6 \%$ da demanda da ETE.

Considerando que a energia na forma de calor nos gases de exaustão (2.000 MJ.d $\left.{ }^{-1}\right)$ não é suficiente para a evaporação de toda a água no lodo desidratado (3.759 kg.d ${ }^{-1}$ ) para se atingir a umidade final de $10 \%$, duas alternativas para o gerenciamento do lodo são consideradas: Alternativa 1: secagem térmica de todo o lodo desidratado até uma umidade final mínima possível; e Alternativa 2: secagem térmica de fração do lodo até uma umidade final de $10 \%$ e o envio do restante do material desidratado (umidade de 58,7\%) para aterro sanitário.

Para a alternativa 1, a umidade mínima possível é de 52,7\% - o lodo possui um elevado teor de umidade para ser aproveitado para fins

Tabela 11 - Balanço de massa para a secagem térmica por combustão de biogás (cenário 1).

\begin{tabular}{|c|c|c|}
\hline Componente & Entrada $\left(\mathrm{kg} \cdot \mathrm{d}^{-1}\right)$ & Saida $\left(k g . d^{1}\right)$ \\
\hline Lodo & 3.759 & 1.725 \\
\hline Biogás $\left(\mathrm{CH}_{4}\right.$ e $\left.\mathrm{CO}_{2}\right)$ & $237^{\mathrm{b}}$ & - \\
\hline Água evaporada & - & $2.034^{a}$ \\
\hline $\operatorname{Ar}\left(\mathrm{O}_{2}\right.$ e N $\left.\mathrm{N}_{2}\right)$ & $567^{b}$ & $31^{b}$ \\
\hline Gases de exaustão $\left(\mathrm{CO}_{2}, \mathrm{O}_{2}, \mathrm{H}_{2} \mathrm{O}\right.$ e $\left.\mathrm{N}_{2}\right)$ & - & $773^{b}$ \\
\hline Total & 4.563 & 4.563 \\
\hline
\end{tabular}

a Valor calculado para a remoção de água de 58,7 a 10\% de umidade. ${ }^{\bullet}$ Valor calculado pelo aplicativo $\mathrm{CHEMCAD}^{\circledR}$

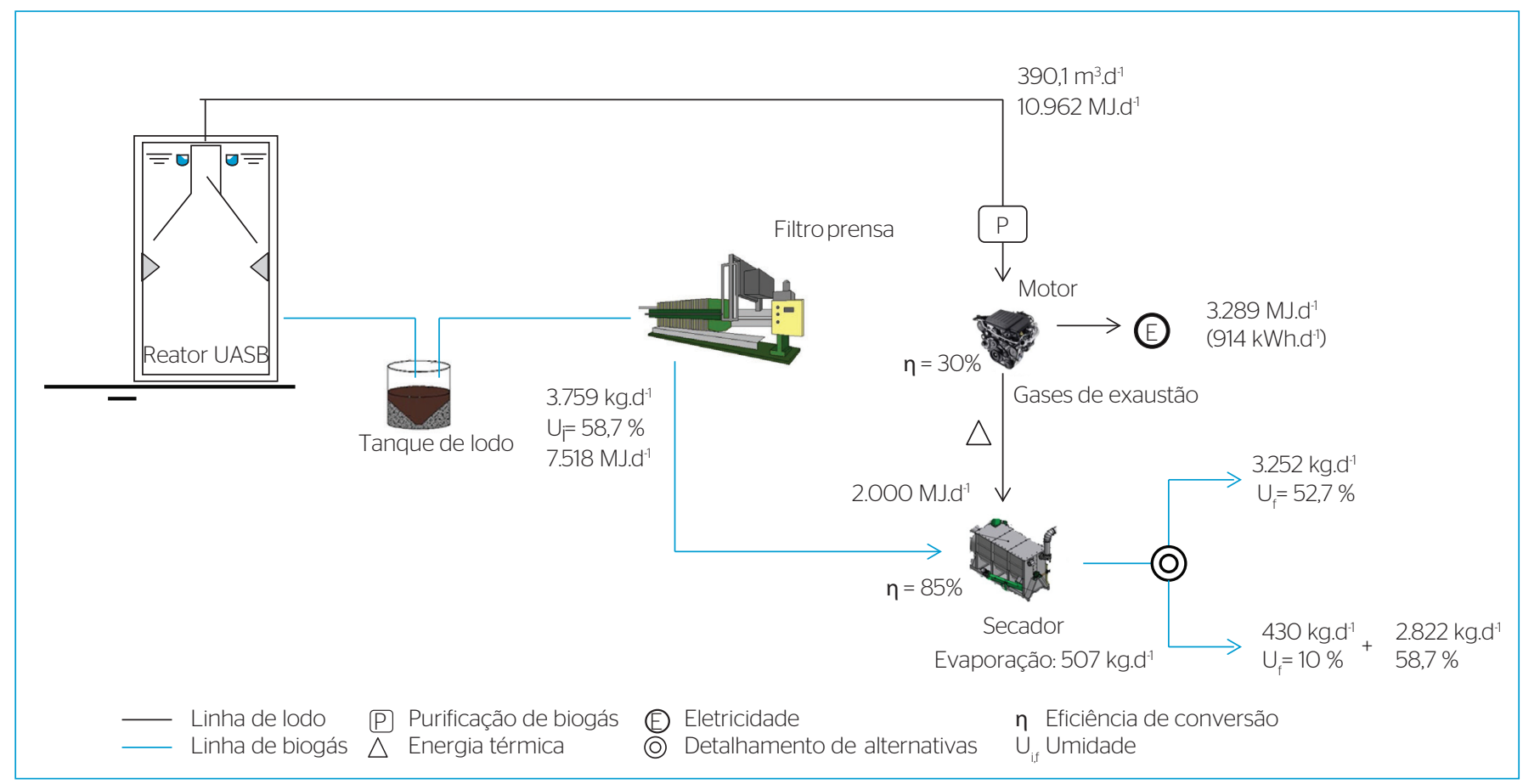

Figura 10 - Balanço de massa e energia para o aproveitamento energético do biogás para a geração de eletricidade seguida de secagem térmica do lodo com os gases de exaustão na estação de tratamento de esgoto Laboreaux (cenário 2). 
energéticos. Entretanto, nessa alternativa o secador promove a redução de massa e volume do lodo a ser enviado ao aterro sanitário.

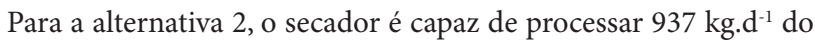
lodo desidratado (que representa $24,9 \%$ do lodo produzido nos filtros prensa), para gerar $430 \mathrm{~kg} . \mathrm{d}^{-1}$ de lodo seco a $10 \%$ de umidade, que pode ser usado como combustível por terceiros. $\mathrm{O}$ restante do lodo não tra-

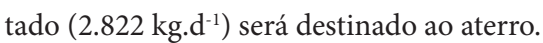

Assim, em termos de massa, a alternativa 1 corresponde a uma redução de 13,5\% da massa de lodos destinada ao aterro e a alternativa 2 corresponde a uma redução maior (24,9\%). Considerando-se uma massa específica de 1.020 e $1.050 \mathrm{~kg} \cdot \mathrm{m}^{-3}$ para a umidade do lodo de 58,7 e 52,7\%, respectivamente, tem-se uma redução de volume de $15,9 \%$ para a alternativa 1 e de $24,9 \%$ para a alternativa 2 . A redução de volume é importante devido aos custos de transporte e disposição final, que são proporcionais à massa e ao volume.

\section{Comparação dos cenários}

A Tabela 13 apresenta um resumo do balanço de energia para ambos os cenários. Com os resultados, pode-se apreender que o cenário 1 apresenta um desempenho para secagem e conversão do

Tabela 12 - Balanço de massa e energia para o cenário 2.

\begin{tabular}{|c|c|c|c|c|c|c|c|}
\hline \multirow[b]{2}{*}{ Item } & \multicolumn{3}{|c|}{ Produtos iniciais } & \multirow[b]{2}{*}{$\begin{array}{l}\text { Perdas } \\
\left(\mathrm{MJ} \cdot \mathrm{d}^{-1}\right)\end{array}$} & \multicolumn{3}{|c|}{ Produtos finais } \\
\hline & Fluxo & Poder calorífico & $\begin{array}{l}\text { Potencial ener- } \\
\text { gético (MJ.d-1 })\end{array}$ & & Fluxo & Poder calorífico & 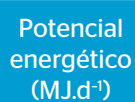 \\
\hline
\end{tabular}

Produtos recebidos da estação de tratamento de esgoto

\begin{tabular}{l|c|c|c|c|c|c|c|}
\hline Lodo (58,7\% umidade) & $3.759{\mathrm{~kg} . \mathrm{d}^{-1}}^{-}$ & $2,0 \mathrm{MJ} \cdot \mathrm{kg}^{-1}$ & 7.518 & - & - & - & - \\
\hline Biogás & $390,1 \mathrm{~m}^{3} \cdot \mathrm{d}^{-1}$ & $28,1 \mathrm{MJ} / \mathrm{m}^{-3}$ & 10.962 & - & - \\
\hline Subtotal & - & - & 18.480 & - & - \\
\hline
\end{tabular}

Balanço no motor de combustão interna

\begin{tabular}{l|c|c|c|c|c|c|c}
\hline Biogás consumido & $390,1 \mathrm{~m}^{3} \cdot \mathrm{d}^{-1}$ & $28,1 \mathrm{MJ} \cdot \mathrm{m}^{-3}$ & 10.962 & - & - & - \\
\hline Energia elétrica gerada $(\eta=30 \%)$ & - & - & - & - & - & - \\
\hline Calor residual nos gases de escape & - & - & - & $7.673^{\mathrm{a}}$ & - & - \\
\hline Subtotal & - & - & 10.962 & 7.673 & - & - \\
\hline
\end{tabular}

Balanço no secador de lodos usando gases do motor de combustão interna - alternativa 1

\begin{tabular}{|c|c|c|c|c|c|c|c|}
\hline Lodo desidratado processado & $3.759 \mathrm{~kg} \cdot \mathrm{d}^{-1}$ & 2,0 MJ.kg-1 & 7.518 & - & - & - & - \\
\hline Lodo final (52,7\% umidade) $)^{b}$ & - & - & - & - & $3.252 \mathrm{~kg} \cdot \mathrm{d}^{-1}$ & 2,31 & $7.518^{*}$ \\
\hline Evaporação da água (†=80\%) & - & - & - & $1.700^{c}$ & - & - & - \\
\hline Perdas por ineficiência no secador & - & - & - & $300^{c}$ & - & - & - \\
\hline Perdas no gás de escapamento & - & - & - & 5.673 & - & - & - \\
\hline Subtotal & - & - & 7.518 & 7.673 & - & - & - \\
\hline Total & - & - & 18.480 & 7.673 & - & - & $10.807^{*}$ \\
\hline
\end{tabular}

Balanço no secador de lodos usando gases do motor de combustão interna - alternativa 2

\begin{tabular}{|c|c|c|c|c|c|c|c|}
\hline Lodo desidratado processado & $3.759 \mathrm{~kg} \cdot \mathrm{d}^{-1}$ & 2,0 MJ.kg $\mathrm{kg}^{-1}$ & 7.518 & - & - & - & - \\
\hline Lodo enviado para aterro $(58,7 \%)^{\mathrm{b}}$ & - & - & - & - & $2.822 \mathrm{~kg} \cdot \mathrm{d}^{-1}$ & 2,0 & 5.644 \\
\hline Lodo energético (10\% umidade) & - & - & - & - & $430 \mathrm{~kg} \cdot \mathrm{d}^{-1}$ & 4,36 MJ.kg-1 & $1.874^{\mathrm{e} *}$ \\
\hline Evaporação da água ( $\eta=80 \%)$ & - & - & - & $1.700^{c}$ & - & - & - \\
\hline Perdas por ineficiência no secador & - & - & - & $300^{d}$ & - & - & - \\
\hline Perdas no gás de escapamento & - & - & - & 5.673 & - & - & - \\
\hline Subtotal & - & - & 7.518 & 7.673 & - & - & $7.518^{*}$ \\
\hline Total & - & - & 18.480 & 7.673 & - & - & 10.807* \\
\hline
\end{tabular}

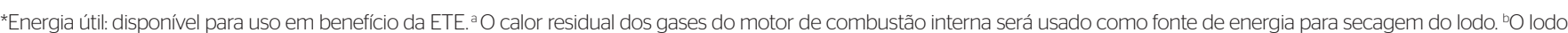
com 52,7\% de umidade não foi considerado passível de uso energético e deverá ser destinado ao aterro sanitário. A secagem tem a finalidade de reduzir massa e volume do lodo.

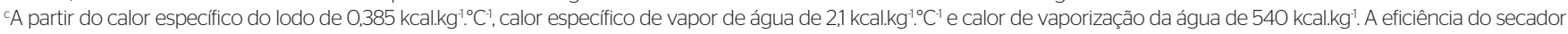

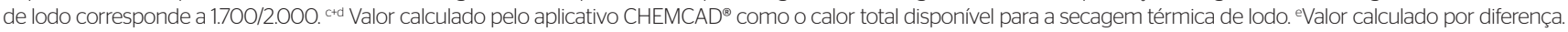


Tabela 13 - Resumo dos cenários para aproveitamento energético para a estação de tratamento de esgoto Laboreaux.

\begin{tabular}{|c|c|c|c|c|}
\hline Itens & Situação atual & Cenário 1 & \multicolumn{2}{|c|}{ Cenário 2} \\
\hline Geração de lodo/rejeito para disposição em aterro (kg.d¹) & 3.759 & - & 3.252 & 2.822 \\
\hline Redução do rejeito em relação à situação atual (\%, massa) & - & 100 & 13,5 & 24,9 \\
\hline Geração de lodo seco biocombustível (10\% umidade) (kg.d-1) & - & 1.725 & - & 430 \\
\hline Suprimento de eletricidade para a ETE (\%) & - & 22,2 & 57,6 & 57,6 \\
\hline
\end{tabular}

ETE: estação de tratamento de efluentes

lodo em subproduto energético, podendo eliminar completamente a geração de rejeitos a serem dispostos em aterro. Em contrapartida, apresenta um menor percentual de suprimento de energia elétrica. A decisão sobre qual é o cenário mais atrativo deve ser feita a partir de análise econômica (análise dos investimentos necessários para cada configuração e os retornos auferidos), a qual extrapola o escopo deste trabalho.

\section{CONCLUSÕES}

A caracterização sistemática da produção e do poder calorífico do biogás e do lodo produzidos na ETE Laboreaux, na cidade de Itabira (MG), possibilitou o desenvolvimento de balanços de massa e de energia que permitiram quantificar o potencial de aproveitamento desses subprodutos do tratamento como fonte de energia renovável, em especial, nas próprias dependências da ETE.

O lodo desidratado de filtro prensa, se for submetido à secagem para melhoria do poder calorífico, pode ser usado como um combustível para abastecer consumidores na região, em substituição da lenha ou do carvão. Já o uso do biogás deve ser feito na própria ETE. O cenário 1 deste estudo refere-se ao emprego do biogás para secagem do lodo até atingir um valor final de $10 \%$ de umidade, com o biogás excedente sendo então usado para gerar eletricidade em motores de combustão interna. O cenário 2 refere-se ao uso integral do biogás para a geração elétrica em motor, sendo os gases de escapamento usados para a secagem do lodo ao máximo possível.

O primeiro cenário se destaca pela eliminação do envio do lodo ao aterro sanitário, enquanto o segundo cenário apresenta elevado potencial de geração de eletricidade em benefício da ETE.

De forma geral, o estudo das alternativas para o aproveitamento energético dos subprodutos do tratamento devem levar em conta as necessidades e realidade das estações. Os balanços de massa e energia são primordiais para a tomada de decisão e podem ser usados para gerar dados necessários aos estudos de viabilidade econômica de projetos de aproveitamento energético que sejam tecnicamente viáveis para cada ETE individualmente.

\section{REFERÊNCIAS}

APHA/AWWA/WEF - AMERICAN PUBLIC HEALTH ASSOCIATION/ AMERICAN WATER WORKS ASSOCIATION/WATER ENVIRONMENT FEDERATION. (1998) Standard Methods for the Examination of Water and Wastewater. 20 ed. Washington DC, USA: APHA/AWWA/WEF.

ARTEAGA, J.A.F. (2010) Análise energética e exergética de um sistema de cogeração com motores de combustão interna. 154 p. Dissertação (Mestrado em Engenharia Mecânica) - Faculdade de Engenharia Mecânica, Universidade Estadual de Campinas, Campinas.

ASSOCIAÇÃO BRASILEIRA DE NORMAS TÉCNICAS. (2006) NBR 8112 Carvão vegetal - análise imediata. Rio de Janeiro.

CORTEZ, L.A.B.; LORA, E.E.S.; GÓMEZ, E.O. (2008) Biomassa para energia. Campinas: Editora Unicamp. 732 p.
COURTAUD, L.; PEREGRINA, C.; CREST, M.; SABLAYROLLES, M.L.; AUDIC, J.M.; ARLABOSSE, P. (2010) Alternative fuels derived from organic waste:the case of sewage sludge characterization as a potential energy source. In: Proceedings of the 13th International symposium on energy from biomass and waste, Venice, Italy.

DE SENA, R.F.; CLAUDINO, A.; MORETTI, K.; BONFANTI, I.C.; MOREIRA, R.F.P.M.; JOSÉ, H.J. (2007) Biofuel application of biomass obtained from a meat industry wastewater plant through the flotation process - A case study. Resources Conservation and Recycling. DOl:10.1016/j. resconrec.2007.07.002.

DOGRU, M.; MIDILLI, A.; HOWARTH, C.R. (2002) Gasification of sewage sludge using a throated downdraft gasifier and uncertainty analysis. Fuel Processing Technology. v. 75, p. 55-82. 
FERNANDES, F.; LOPES, D.D.; ANDREOLI, C.V.; SILVA, S.M.C.P. (2001) Avaliação de alternativas e gerenciamento do lodo na ETE. In: ANDREOLI, C.V.; VON SPERLING, M.; FERNANDES, F. Lodo de esgotos: tratamento e disposição final. Cap. 7, p. 299-317.

FONTS, I.; AZURA, M.; GEA, G.; MURILLO, M.B. (2009) Study of the pyrolysis liquids obtained from different sewage sludge. Journal of Analytical and Applied Pyrolysis, v. 85, p. 184-191.

GROß, B.; EDER, C.; GRZIWA, P.; HORST, J.; KIMMERLE, K. (2008) Energy recovery from sewage sludge by means of fluidized bed gasification. Waste Management, v. 28, p.1.819-1.826.

HOLM-NIELSEN, J.B.; AL SEADI, T.; OLESKOWICZ-POPIEL, P. (2009) The future of anaerobic digestion and biogas utilization. Bioresource Technology, v. 100, p. 5478-5484

HOUDKOVÁ, L.; BORAN, J.; UCEKAJ, V.; ELSASER, T.; STEHLIK, P. (2008) Thermal processing of sewage sludge - II. Applied Thermal Engineering, v. 28, p. 2083-2088.

JENKINS, B.M. (1990) Fuel properties for biomass materials. In: International symposium on application and management of energy in agriculture: the role of biomass, 1990, Delphi. apud CORTEZ, L. A. B.; LORA, E. E. S.; GOMEZ, E. O. (2008) Biomassa para energia. Campinas: Editora Unicamp, 732 p.

JUDEX, JW.; GAIFFI, M.; BURGBACHER, C. (2O12) Gasification of dried sewage sludge: Status of the demonstration and pilot plant. Waste Management, v. 32, p. 719-723.

KELESSIDIS, A. \& STASINAKIS, A.S. (2012) Comparative study of the methods used for treatment and final disposal of sewage sludge in European countries. Waste Management, v. 32, p. 1186-1195.
LOBATO, L.C.S.; CHERNICHARO, C.A.L.; PUJATTI, F.J.P.; MARTINS, O.M.; MELO, G.C.B.; RECIO A.A.R. (2012) Use of biogas for cogeneration of heat and electricity for local application: performance evaluation of an engine power generator and a sludge thermal dryer. Water Science and Technology, v. 67, n. 1, p. 159-167.

METCALF \& EDDY. INC. (2003) Wastewater Engineering treatment Disposal Reuse. 4 ed. New York: McGraw-Hill Book, 1815 p.

NOYOLA, A.; MORGAN-SAGASTUME, J.M.; LÓPEZ-HERNÁNDEZ, J.E. (2006) Treatment of biogas produced in anaerobic reactors for domestic wastewater: odour control and energy/resource recovery. Reviews in Environmental Sciences and Bio/Technology, v. 5, p. 93-114.

SALOMON, K.R.; LORA, E.E.S. (2009) Estimate of the electric energy generating potential for different sources of biogas in Brazil. Biomass and Bioenergy, v. 33, p. 1101-1107.

STASTA, P.; BORAN, J.; BEBAR, L.; STEHLIK, P.; ORAL, J. (2006) Thermal processing of sewage sludge. Applied Thermal Engineering, v. 26, p. $1420-1426$

TSAGARAKIS, K.P. (2007) Optimal number of energy generators for biogas utilization in wastewater treatment facility. Energy Conversion and Management, v. 38, p. 2694-2698.

UE - União Europeia. Disponível em: http://epp.eurostat.ec.europa.eu. Acesso em 25 set 2011.

VAN KREVELEN, D.W. \& SCHUYER, J. (1957) Coal Science. Amsterdam: Elsevier Publishing Company. 